\title{
The Evaluation of Water Treatment Methods Utilized among Households in Kyegegwa District, Uganda
}

\author{
Nwanna Uchechukwu Kevin \\ Faculty of Health Sciences, Victoria University Uganda, Kampala, Uganda \\ Email: uchenwanna1@gmail.com, uche4score@yahoo.com
}

How to cite this paper: Kevin, N.U. (2019) The Evaluation of Water Treatment Methods Utilized among Households in Kyegegwa District, Uganda. Health, 11, 1291-1298.

https://doi.org/10.4236/health.2019.1110099

Received: August 8, 2019

Accepted: October 13, 2019

Published: October 16, 2019

Copyright $\odot 2019$ by author(s) and Scientific Research Publishing Inc. This work is licensed under the Creative Commons Attribution International License (CC BY 4.0).

http://creativecommons.org/licenses/by/4.0/

\begin{abstract}
Introduction: The Health sector continues to prioritize interventions defined in the Uganda National Minimum Health Care Package under a Sector-Wide Approach arrangement, with emphasis on recommendations of the HSSIP 2010/11-2014/15 Mid-Term review. This is further supported by the resolutions of the World Health Assembly, the International Health Partnerships, the Paris Declaration on Harmonization and Alignment and the Accra Agenda for Action and related initiatives. Objective: The purpose of this study was to evaluate the various water treatment methods utilized among the various households in Kyegegwa district in Uganda. Methodology: A cross-sectional study was carried out among 397 different households in Kyegegwa district. Data were analyzed using SPSS to generate descriptive data. Results: Slightly more than half of the households used boiling as the treatment methods of choice 206 (51.9\%), filtration 104 (26.2\%), chlorination 24 (6\%), solar disinfection 16 (4\%) and I don't treat water 47 (11.8\%). Conclusion: The identified water treatments methods used among the households in Kyegegwa district were boiling, filtration, chlorination and solar disinfection. Recommendation: Health education should be provided on the importance of treating water by boiling and storing them in a cleaned and covered container.
\end{abstract}

\section{Keywords}

Water Treatment, Kyegegwa District, Health Education, Boiling

\section{Introduction}

National Water Policy in Uganda goes thus: Separation of regulatory powers from user interests; Integrated and sustainable development, management and 
use of water resources with full participation of all stakeholders; Regulated use of all water other than for domestic use; Sustainable provision of clean safe water; Development and efficient use of water in agriculture; Improved collaboration and coordination among stakeholders; Equitable access and use of the Nile waters (trans-boundary water resource); Promotion of awareness of water management and development issues and capacity building; Promotion of rational, optimal and wise use of the resource for all Ugandans and all sectors; Promotion of measures for control of pollution of water resources; Promotion of the gathering and maintenance of reliable water resources information and databases; Promotion of viable management options for the resource management and provision of water supply and sanitation services (National Water Policy, 1999) [1].

The Strategies include: Establishment of an enabling environment; Development of appropriate institutional framework; Planning and prioritization of water use; Data collection and data dissemination and Capacity building (Baguma, D., et al., 2013) [2]. According to the water quality monitoring work, which was carried out by the Directorate of Water Resources Management (DWRM) of MWE, the compliance of rural safe drinking water sources to national water quality standards was $53 \%$ (E. coli being the key indicator), against a target of $95 \%$ (WESPR, 2014) [3].

Safe water, adequate sanitation, and proper hygiene education (WSH) can prevent illness and death, leading to improved health, poverty reduction, and socio-economic development (Bartram and Cain cross, 2010) [4]. In addition, Water is one of the key determinants to life among the element of WASH. Lack of these three elements makes people more susceptible to illness and death.

Safe water, coupled with adequate sanitation, and proper hygiene education (WASH) can prevent illness and death, leading to improved health, poverty reduction, and socio-economic development (Bartram and Cain cross, 2010) [4]. Household water treatment, also known as point of use water treatment (POU), such as boiling, filtration and chlorination, has been shown to be an effective means of reducing diarrhoea and other diseases associated with unsafe drinking water (Sobsey MD, 2002) [5].

According to a study conducted in Tanzania, 2012, which was done to determine the proportional of water treatment methods locally available and accessible to the respondents; it was found that about $49.5 \%$ reported treating their water with any method such as boiling, strain in cloth, use of chlorine and let it stand and Settle. It was also found out in the same study conducted in Tanzania by (Remidius $\mathrm{K}$, in 2012) [6] that the majority of respondents reported using buckets, soil pots, jerry cans and small pan for storing drinking water.

The Directorate of Water Resources Management (DWRM) of MWE in Ugan$\mathrm{da}$, revealed that the compliance of rural safe drinking water sources to national water quality standards was $53 \%$ (E. coli being the key indicator), against a target of 95\% (WESPR, 2014) [3]. US \$ 147 million is lost each year due to premature 
deaths; approximately 23,000 Ugandans die each year from water borne diseases nearly $90 \%$ of which is directly attributed to poor water, sanitation and hygiene (Kolawole, A.K., et al., 2012) [7].

\section{Methodology}

\subsection{Study Design}

The research design for this study was a cross-sectional descriptive design, in which data was collected and analyzed largely by quantitative method. It used descriptive design because it offered a precise description and information of the household based water treatments methods as they exist.

\subsection{Study Population}

The study population was 59,332 been the number of households in Kyegegwa district on accounts of studying each household.

\subsection{Target Respondents}

The target respondents included for the study most be aged 18 years and above with sound state of mind and should be able to speak and understand English language or the local dialects as questionnaire will be verbally translated into Rutooro/Bunyoro, Ruganda and Rukiga.

The target respondent most also be living in the house unit included for study.

\subsection{Sample Size}

The sample size of the study was determined by using Slovene's formula which states that:

$$
n=\frac{N}{1+N e^{2}}
$$

where: $n=$ Unknown sample size;

$N=$ Total population of the study $(59,332$, UBOS, 2016) [8];

$(e)=$ level of significance $=(0.05)^{2}$;

$1=$ constant;

$n=397$.

\subsection{Sampling Technique}

The sampling technique was a multi stage cluster. The district has one County, Kyaka and nine sub-counties, namely: 1. Hapuuyo; 2. Kabweeza; 3. Kakabara; 4. Kasule; 5. Kyaka; 6. Kyegegwa town council; 7. Mpara; 8. Ruyonza and 9. Rwentuha, after clustering the sub-counties, each of the sub-counties was sampled using a simple random sampling (Table 1).

\subsection{Data Collection Methods and Tools}

A close ended structured researcher self-administered questionnaire for the 
Table 1. Distribution of the sample among sub-counties of Kyegegwa District $(n=397)$.

\begin{tabular}{ccccc}
\hline District & County & Sub-county & $\begin{array}{c}\text { Household } \\
\text { (Population) }\end{array}$ & $\begin{array}{c}\text { Household } \\
\text { (Sample) }\end{array}$ \\
\hline \multirow{6}{*}{ Kyegegwa } & Kyaka & Hapuuyo & 9825 & 66 \\
& Kyaka & Kabweeza-kyegegwa & 5445 & 36 \\
& Kyaka & Nakabara & 10,495 & 70 \\
& Kyaka & Kasule & 5140 & 35 \\
& Kyaka & Kyaka & 4398 & 29 \\
& Kyaka & Kyegegwa t/council & 4416 & 30 \\
& Kyaka & Mpara & 7071 & 47 \\
& Kyaka & Ruyonza & 5043 & 34 \\
& Kyaka & Rwentuha & 7499 & 50 \\
& & & $\mathbf{N}=59,332$ & $\mathbf{n}=\mathbf{3 9 7}$ \\
\hline
\end{tabular}

household's. The questionnaire was prepared to cover all necessary questions about the variables under study.

A research assistant was employed for the data collection after being trained to minimized bias.

Tools will pre-test to ensure validity.

\subsection{Measurements of Variables}

\subsubsection{Independent Variable}

Attributes such as households in Kyegegwa district in Uganda were controlled by using essential questions related to each attribute.

\subsubsection{Dependent Variable}

Water treatment methods were measured using the following: attributes boiling, filtration, solar disinfection and chlorination.

\subsection{Data Analysis and Interpretation}

The data was collected and processed into tables using SPSS computer software and Microsoft excel program.

\subsection{Quality Control}

The research tools of this study were subjected to a pre-test, so as to assess the validity and reliability of data that would be collected for the study.

\subsection{Ethical Consideration}

An introductory letter from the University, addressed to the district health officer (DHO) was collected, endorsed and approved to conduct the study.

The consent to conduct the study in Kyegegwa district was sought by the district health officer (DHO).

The consent of respondent was sought, to participate in the research after cit- 
ing the reasons why the research is been conducted and there right to withdraw from the study at any time of data collection process was clearly explained to respondents.

\subsection{Limitations of the Study}

The study encountered challenges of research assistance unwillingness to complete the questions under each questionnaire which was overcome by making sure that each questionnaire was labeled with the name of interviewer so as to be able to trace uncompleted questionnaires after data collection.

\section{Results}

As regards to water treatment methods, it was found that slightly more than half of the respondents used boiling as the treatment methods of choice 206 (51.9\%); however, for those who used filtration majority mentioned they let it stand and settle/filter with clean cloth 80 (76.9\%). For those who utilized chlorination, most of them 9 (37.5\%) mentioned that they filtered 20litres and added to 2tabs of chlorine, in addition the respondents who used solar disinfection, most stated that they filtered 20litres and put in a clean container $11(68.8 \%)$, finally majority of the respondents stated that the reason why they don't treat their water was due to the cost involved in water treatment 14 (29.8) (Table 2).

\section{Discussion}

\section{Water Treatment Methods Used among Households}

Regarding the water treatment methods, it was found that slightly more than half of the respondents used boiling as the treatment methods of choice 206 (51.9\%), followed by filtration 104 (26.2\%),chlorination 24 (6.0\%), solar disinfection $16(4.0 \%)$ and those who said I don't know 47 (11.8\%) respectively. However, for those who used filtration majority mentioned that they let it stand and settle/Filter with clean cloth 80 (76.9\%). For those who used chlorination, most of them 9 (37.5\%) mentioned that they filtered 20 ltrs and added to 2 tabs. For the respondents who used solar disinfection, most stated that they filtered 20 ltrs and put in a clean container $11(68.8 \%)$, majority of the respondents stated that the reason why they don't treat their water was due to the cost involved in water treatment 14 (29.8). It was also seen in a slightly similar study conducted by (Ghislaine Rosa in 2010) [9], where he extracted data from the National Surveys as a retrospective study and reports on scope of household water treatment in sixty seven (67) countries worldwide indicated that the proportion of water treatment by boiling in Uganda was (39.8\%) and Zambia (15.2\%) whereby in Latin America chlorine is practiced by $17.1 \%$ of the households while Guinea Bissau (70.9\%) and Mali (24.0\%) strain drinking water through cloth.

Also in a study conducted in Tanzania by Remidius Kakulu, where he determined the proportional of respondents who treat their drinking water with any method locally available and accessible to them. It was also found that about 
Table 2. Distribution of water treatment methods used among households of Kyegegwa district.

\begin{tabular}{|c|c|c|}
\hline Method & Frequency & Percent \\
\hline \multicolumn{3}{|l|}{ Treatment of drinking water (method used) } \\
\hline Boiling & 206 & 51.9 \\
\hline Filtration & 104 & 26.2 \\
\hline Chlorination & 24 & 6.0 \\
\hline Solar disinfection & 16 & 4.0 \\
\hline I don't treat & 47 & 11.8 \\
\hline Total & 397 & 100.0 \\
\hline \multicolumn{3}{|l|}{ Filtration } \\
\hline Let it stand and settle/filter with clean cloth & 80 & 76.9 \\
\hline All of the above & 24 & 23.1 \\
\hline Total & 104 & 100.0 \\
\hline \multicolumn{3}{|l|}{ Chlorination } \\
\hline Filter 20 ltrs & 7 & 29.2 \\
\hline Filter 20 ltrs and add to 2 tabs & 9 & 37.5 \\
\hline All of the above & 8 & 33.3 \\
\hline Total & 24 & 100.0 \\
\hline \multicolumn{3}{|l|}{ Solar disinfection } \\
\hline Filter 20 ltrs and Put in a clean container & 11 & 68.8 \\
\hline Display in sun for $2 \mathrm{hrs}$ & 5 & 31.2 \\
\hline Total & 16 & 100.0 \\
\hline \multicolumn{3}{|l|}{ Reasons for not treating water } \\
\hline Available & 7 & 14.9 \\
\hline Cost & 14 & 29.8 \\
\hline Bad taste and smelly of treatment & 11 & 23.4 \\
\hline I believe water is safe from the source & 10 & 21.3 \\
\hline I am used to drinking Untreated water and nothing happen to me & 4 & 8.5 \\
\hline I don't know & 1 & 2.1 \\
\hline Total & 47 & 100.0 \\
\hline
\end{tabular}

$49.5 \%$ of the respondents in the study reported treating their drinking water with any method (boiling, strain in cloth, use of chlorine/chlorination and Let it stand and Settle).Water treatment by boiling and Let it stand and Settle were frequently practiced by respondents as methods of water treatment, few of the respondents reported using water guards and strain in cloth, where boiling was the most utilized among the households which was in line to this research study.

This research study stresses the need to boil and treat all water for domestic use in every households not only in the district of Kyegegwa; but should be adopted as a global measure especially in rural areas where infectious diseases 
tends to spread rapidly thereby causing untimely deaths and widespread poverty. However, despite this research results revealed boiling as major source of water treatment, other methods can be combined with boiling in order to kill $99.99 \%$ of bacteria that lives and reproduce in water. In addition, if water sources are consumed without any form of treatment diseases such as cholera, dysentery, typhoid, diarrhoea, etc., will spread like wildfire thereby causing a population decrease due to death and economic breakdown due to loss of skills and manpower; thus water treatment should never be under looked nor taken for granted.

\section{Conclusion}

This study concluded that the identified water treatments methods utilized among the households in Kyegegwa district were boiling, filtration, chlorination and solar disinfection.

\section{Recommendations}

Health education should be provided on the importance of treating water by boiling and storing them in clean and covered containers.

\section{Conflicts of Interest}

The author declares no conflicts of interest regarding the publication of this paper.

\section{References}

[1] National Water Policy (1999).

[2] Baguma, D., Hashim, J.H., Aljunid, S.M. and Loiskandl, W. (2013) Safe-Water Shortages, Gender Perspectives, and Related Challenges in Developing Countries: The Case of Uganda. Science of the Total Environment, 442, 96-102. https://doi.org/10.1016/j.scitotenv.2012.10.004

[3] Ministry of Water and Environment Uganda (2014) Water and Environment Sector Performance Report.

[4] Bartram, J. and Cairncross, S. (2010) Hygiene, Sanitation, and Water: Forgotten Foundations of Health. PLoS Med, 7, e1000367. https://doi.org/10.1371/journal.pmed.1000367

[5] Sobsey, M.D. and the World Health Organization (2002) Managing Water in the Home: Accelerated Health Gains from Improved Water Supply.

[6] Kakulu, R.K. (2012) Diarrhoea among Underfive Children and Household Water Treatment and Safe Storage Factors in Mkuranga District, Tanzania. Muhimbili University of Health and Allied Sciences, Dar es Salaam.

[7] Kolawole, A.K., Jibrin, A., Catherine, S.O., Oluwole, I. and Kevin, N.U. (2012) Household-Based Water Storage and Diarrheal Diseases among Residents of Kyegegwa District of Western Uganda.

[8] Uganda Bureau of Statistics (2016) The National Population and Housing Census 2014. Main Report, Kampala.

[9] Rosa, G. and Clasen, T. (2010) Estimating the Scope of Household Water Treatment in Low and Medium Income Countries. The American Journal of Tropical Medicine and Hygiene, 82, 289-300. https://doi.org/10.4269/ajtmh.2010.09-0382 


\section{Appendix}

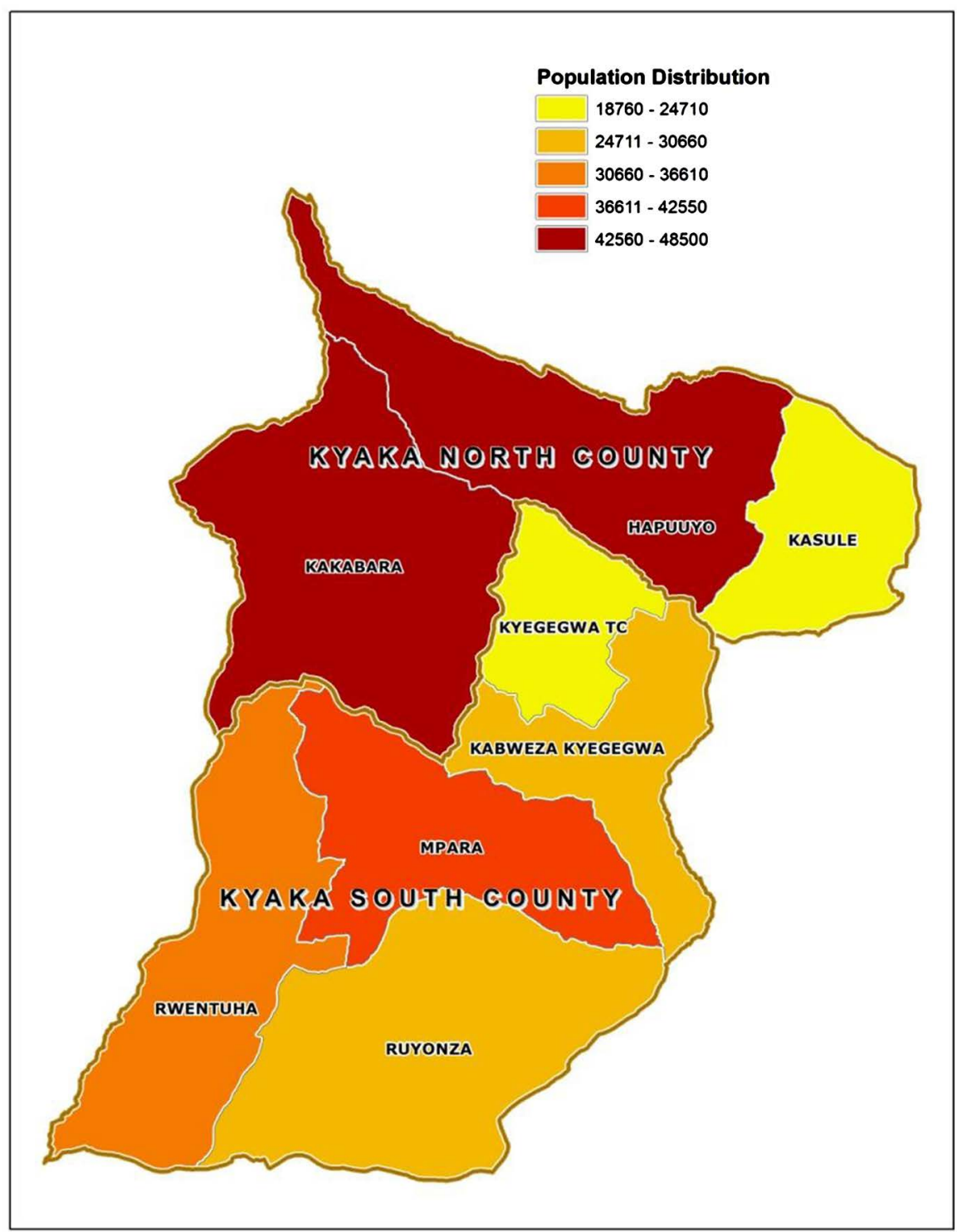

Adapted from: National Population and Housing Census 2014. 